\title{
Disseminated Cutaneous Mycobacterium Chelonae Infection in a 9.5-Year-Old Girl with Diabetes
}

\author{
Crisinel $\mathrm{PA}^{* 1}$, Jaton $\mathrm{K}^{2}$, Abbo $\mathrm{O}^{3}$, Hiroz $\mathrm{S}^{4}$ and Hauschild $\mathrm{M}^{4}$
}

${ }^{1}$ Department of Pediatrics, Lausanne University Hospital, Lausanne, Switzerland

${ }^{2}$ Institute of Microbiology, Lausanne University Hospital, Lausanne, Switzerland

${ }^{3}$ Department of Pediatric Surgery, Lausanne University Hospital, Lausanne, Switzerland

${ }^{4}$ Division of Pediatric Endocrinology, Diabetology and Obesity, Department of Pediatrics, Lausanne University Hospital, Lausanne, Switzerland

${ }^{*}$ Corresponding author: Crisinel PA, Department of Pediatrics, Lausanne University Hospital, Hospital for Children, Path Montétan 16, 1000 Lausanne 7, Switzerland, Fax: +41 213148630, Telephone: +41795568627 , E-mail: Pierre-Alex.Crisinel@chuv.ch

Citation: Crisinel PA, Jaton K, Abbo O, Hiroz S, Hauschild M (2015) Disseminated Cutaneous Mycobacterium Chelonae Infection in a 9.5-Year-Old Girl with Diabetes. J Case Rep Stud 3(6): 601. doi: 10.15744/23489820.3.601

Received Date: August 7, 2015 Accepted Date: December 11, 2015 Published Date: December 14, 2015

\begin{abstract}
Mycobacterium chelonae is a fast growing mycobacteria that mainly causes localized cutaneous infections. Disseminated cutaneous infections are quite exclusively seen in immunosuppressed individuals. We present a case of disseminated cutaneous infection in a young diabetic patient. This case underscores the need to consider atypical mycobacterial infections in any patient with culture-negative cutaneous infections resistant to conventional antibiotic treatment.

Keywords: Mycobacterium chelonae, Infectious Complications, Pediatric Diabetes, Mycobacteria

List of Abbreviations: M. chelonae: Mycobacterium chelonae; ATS: American thoracic society; IDSA: Infectious Diseases Society of America
\end{abstract}

\section{Introduction}

Atypical mycobacterial infections can occur at subcutaneous insulin injection sites. These infections are often misdiagnosed. Herein, we report a case of disseminated cutaneous Mycobacterium chelonae (M. chelonae) infection in a pediatric patient with type 1 diabetes mellitus.

\section{Case report}

A 9.5-year-old girl with type 1 diabetes presented with an inflammatory nodule of her right buttock at the site of a previous insulin injection. She had been followed since her diagnoses 3 years prior and her diabetes had been well-controlled (most recent HbA1c 7.1\%, mean HbA1c over the previous 12 months: 7.9\%, insulin requirements: $0.76 \mathrm{U} / \mathrm{kg} /$ day). When she presented for evaluation of the nodule she was being treated with an intensified basal bolus insulin regime using insuline lispro and insuline glargine. The patient and the parents reported regular changing of insulin needles and local disinfection at injection site. Over the course of one week, the lesion evolved to an abscess requiring incision and drainage. Classical bacterial cultures remained negative.

Despite oral antibiotic therapy (co-amoxicillin, clindamycin), the infection recurred and similar lesions appeared on both thighs bilaterally over the subsequent weeks, some of which discharging spontaneously (Figure 1). Additional bacterial and fungal cultures of the discharging collection remained negative but mycobacterial culture was positive for M. chelonae. Culture was performed in a mycobacterium growth indicator tube (MGIT) (Becton Dickinson Microbiology Systems) in a modified Middlebrook 7H9 broth and incubated in Bactec MGIT 960. When positive, Ziehl-Neelsen staining was performed in order to confirm the presence of acid-fast bacilli. The identification of the mycobacterial isolates was performed by sequencing and analysis of $16 \mathrm{~S}$ rRNA, hsp 65 and rpoB genes [1]. Laboratory assessment of immunity (immunoglobulins and complement) was normal. ATS/IDSA guidelines recommend to start with a combination therapy for severe infection [1]. However, as the lesions were limited in their extension, we opted for a monotherapy of clarithromycin $(10 \mathrm{mg} / \mathrm{kg}$ bid) which could be started about 2 months after the first symptoms (Figure 2 ). The patients tolerated the regimen well and responded favorably over the next 6-months of treatment without recurrence of lesions. 


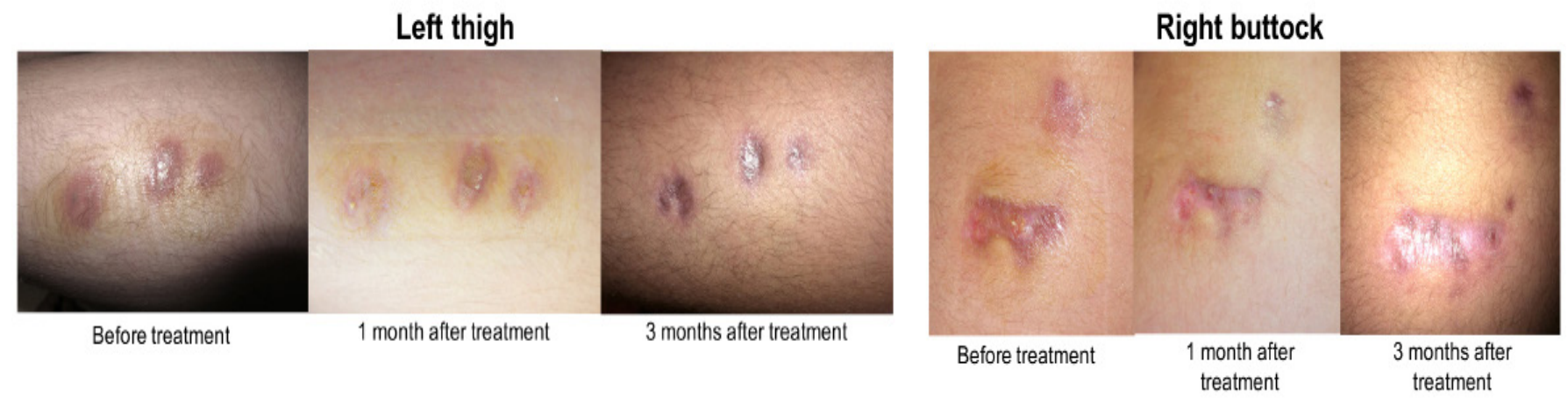

Figure 1: Lesions appeared on both thighs

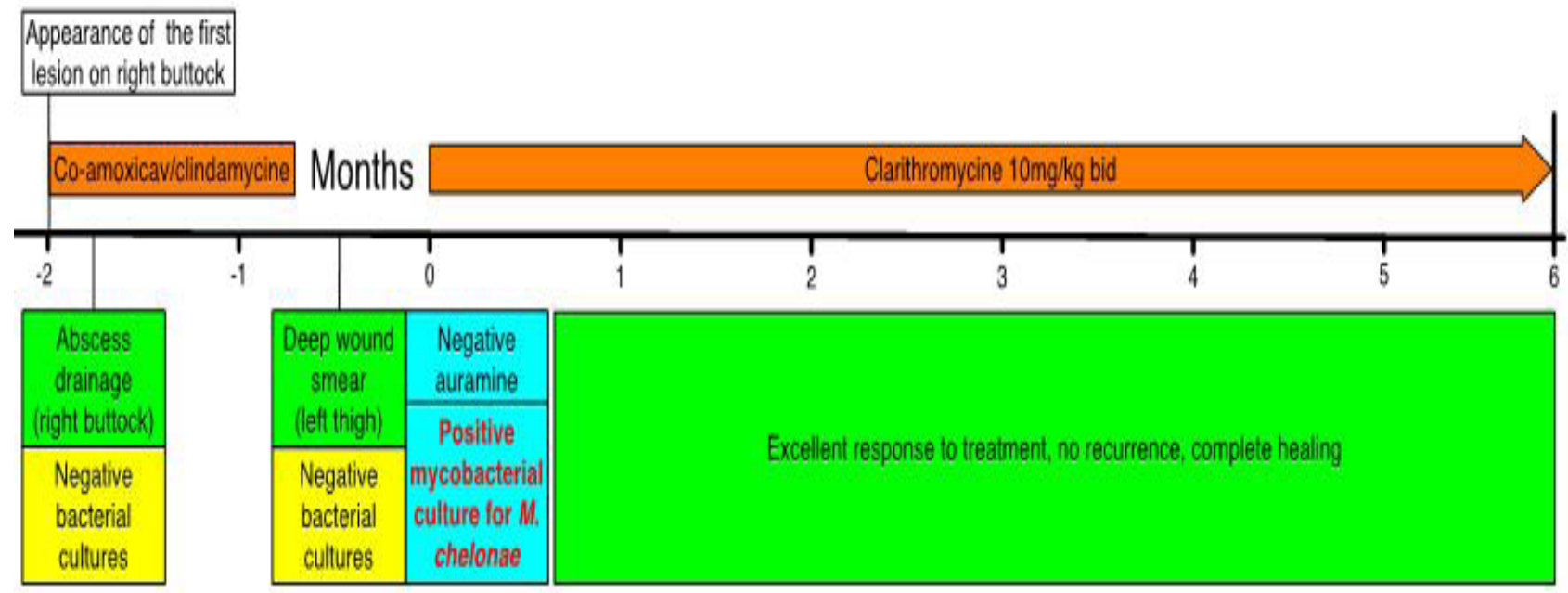

Figure 2: Monotherapy of clarithromycin (10 mg/kg bid) 2 months after the first symptoms

\section{Discussion}

While several case-reports and one series have been described in adult patients with diabetes (Table 1) [2-5], a pediatric case of $M$. chelonae infection in relation to type 1 diabetes has not been reported. $M$. chelonae is a rapidly growing saprophyte mycobacteria found in soil, water, and dust [6] and is typically associated with localized cutaneous or soft-tissue infections. Abscesses, cellulitis and subcutaneous nodules are typically described. Disseminated cutaneous infections are almost exclusively observed in immunosuppressed individuals, as are more severe complications such as osteomyelitis, endocarditis, peritonitis, sepsis, meningitis or pneumonitis [1]. Infection primarily occurs by direct inoculation of the skin with contaminated cosmetic [7] or medical [8] equipment. In the present case, we were unable to culture any of the the injection materials as these products were changed early during the course of the infection. Investigations of the injection techniques did not reveal any other source of infection. The possibility of a host susceptibility to mycobacterial infections (such as a mendelian susceptibility to mycobacterial disease [9]) was estimated to be very low according to the absence of a relevant past history and the good response to treatment. Therefore, no further investigation was done. M. chelonae is usually sensitive to clarithromycin and requires a long course of treatment to obtain a sustained cure [10]. Relapse is common and may indicate antibiotic resistance that can occur during prolonged treatment [11]. Fortunately we did not face problems of resistance, despite the choice of a monotherapy.

\begin{tabular}{|c|c|c|c|c|c|}
\hline $\begin{array}{c}\text { Refer- } \\
\text { ence }\end{array}$ & $\begin{array}{c}\text { Type of publi- } \\
\text { cation }\end{array}$ & Number of patients & Ages of patients & $\begin{array}{c}\text { Type and duration of symp- } \\
\text { toms before treatment }\end{array}$ & Antibiotic use and outcome \\
\hline 2 & Case series & $\begin{array}{c}3 \text { diabetic patients out } \\
\text { of } 100 \text { patients }\end{array}$ & Unknown & $\begin{array}{c}\text { Localized cutanous lesions. } \\
\text { Duration unknown }\end{array}$ & unknown \\
\hline 3 & Case report & 1 & 60 yo & $\begin{array}{c}\text { Disseminated cutaneous } \\
\text { lesions. } \\
4 \text { months }\end{array}$ & $\begin{array}{c}\text { Doxycyclin, ciprofloxacin, clarithromy- } \\
\text { cin. } \\
\text { Complete healing }\end{array}$ \\
\hline 4 & Case report & 1 & 43 yo & $\begin{array}{c}\text { Cutaneous, disseminated. } \\
5 \text { months }\end{array}$ & $\begin{array}{c}\text { Ciprofloxacin, clarithromycin. } \\
\text { Complete healing }\end{array}$ \\
\hline 5 & Case report & 1 & 49 yo & $\begin{array}{c}\text { Disseminated cutaneous } \\
\text { lesions. } \\
4 \text { months }\end{array}$ & $\begin{array}{c}\text { Clarithromycin, tobramycin. } \\
\text { Recurrence of one nodular lesion under } \\
\text { treatment before complete healing }\end{array}$ \\
\hline
\end{tabular}

Footnote: all patients had insulin-dependant diabetes mellitus (either type 1 or 2) and all infections were confined to the skin.

Table 1: Case-reports and one series in adult patients with diabetes 


\section{Conclusion}

This case underscores the need to consider atypical mycobacterial infections in any patient with culture-negative injection site infections resistant to conventional antibiotic treatment.

\section{Acknowledgment}

We thank Andrew Dwyer of the Service of Endocrinology, Diabetology and Metabolism of Lausanne University Hospital, for help in the preparation of this manuscript.

\section{References}

1. Griffith DE, Aksamit T, Brown-Elliott BA, Catanzaro A, Daley C, et al. (2007) An official ATS/IDSA statement: diagnosis, treatment, and prevention of nontuberculous mycobacterial diseases. Am J Respir Crit Care Med 175: 367-416.

2. Wallace RJ, Brown BA, Onyi GO (1992) Skin, soft tissue, and bone infections due to Mycobacterium chelonae chelonae: importance of prior corticosteroid therapy, frequency of disseminated infections, and resistance to oral antimicrobials other than clarithromycin. J Infect Dis 166: 405-12.

3. Schadlow M, Laochumroonvorapong P, Burack L, Wu H, Sinha AA (2003) Nodules on the arm of a diabetic patient. Arch Dermatol 139: 93-8.

4. Finucane K, Ambrey P, Narayan S, Archer CB, Dayan C (2003) Insulin injection abscesses caused by Mycobacterium chelonae. Diabetes Care 26: 2483-4.

5. Escobedo JA, Gil D, Pascual A, Aguirre JM (1994) [Cutaneous infection caused by Mycobacterium chelonae after self-injection of insulin using a jet injector]. Enferm Infecc Microbiol Clin 12: 274-5.

6. Kullavanijaya P (1999) Atypical mycobacterial cutaneous infection. Clin Dermatol 17: 153-8.

7. Sergeant A, Conaglen P, Laurenson IF, Claxton P, Mathers ME, et al. (2013) Mycobacterium chelonae infection: a complication of tattooing. Clin Exp Dermatol 38: $140-2$.

8. Hay RJ (2009) Mycobacterium chelonae--a growing problem in soft tissue infection. Curr Opin Infect Dis 22: 99-101.

9. Bustamante J, Boisson-Dupuis S, Abel L, Casanova JL (2014) Mendelian susceptibility to mycobacterial disease: genetic, immunological, and clinical features of inborn errors of IFN- $\gamma$ immunity. Semin Immunol 26: 454-70.

10. Wallace RJ, Silcox VA, Tsukamura M, Brown BA, Kilburn JO, et al. (1993) Clinical significance, biochemical features, and susceptibility patterns of sporadic isolates of the Mycobacterium chelonae-like organism. J Clin Microbiol 31: 3231-9.

11. Wallace RJ, Tanner D, Brennan PJ, Brown BA (1993) Clinical trial of clarithromycin for cutaneous (disseminated) infection due to Mycobacterium chelonae. Ann Intern Med 119: 482-6. 